\section{Not only synovitis but also tenosynovitis needs to be considered: why it is time to update textbook images of rheumatoid arthritis}

Rheumatoid arthritis (RA) is typically represented as synovitis and bone erosions of small joints. This classic picture resulted from comparing patients with RA with other rheumatic joint diseases for clinical and radiographic characteristics. Although different classification criteria for RA have been developed over time, this classic picture has not changed since the mid-20th century. During the last decennium, advanced imaging modalities, such as MRI and musculoskeletal ultrasound (US), have refined our understanding of tissues involved in RA. We will argue that tenosynovitis at the level of the hand and feet joints is a feature that deserves to be added as the third classic trait of RA.

A feature can be considered as a disease trait when it occurs frequently and is specific, and when a new trait is considered its connection with the disease is not a substitute of an already acknowledged classic feature. We will study the occurrence of tenosynovitis in RA in the light of these principles.

Many, but not all, tendons at the hand and feet joints are surrounded by a sheath. ${ }^{12}$ Tendon sheaths have a cell composition similar to the synovial lining of joints. ${ }^{3}$

Fiona McQueen was the first to describe tenosynovitis in early RA using MRI. ${ }^{4}$ The reported prevalence of tenosynovitis depends on the number of tendon sheaths studied (wrist, metacarpophalangeal (MCP) and/or metatarsophalangeal (MTP) joints, unilateral or bilateral). A prevalence of $\sim 50 \%$ is described, ${ }^{56}$ but most were higher $(\sim 80 \%) .{ }^{7-11}$ MRI studies in consecutive early RA showed a sensitivity of tenosynovitis of 75\%-87\%. ${ }^{7-9}$ Figure $1 \mathrm{~A}-\mathrm{C}$ presents imaging examples (MRI, US) in early RA. Imaging studies in persons from the general population repetitively showed a prevalence of tenosynovitis at small joints ranging from $0 \%$ to $3 \%,{ }^{12-14}$ corresponding with a specificity of $97 \%-100 \%$. The specificity in patients with other arthritides as reference is also high. A study at the tendon level of the wrist and MCP joints, comparing consecutive patients with RA and other early arthritis (including psoriatic arthritis), reported a specificity ranging from $82 \%$ to $99 \% .{ }^{8}$ Thus, tenosynovitis at the level of small joints (MCPs, wrist, MTPs) has high sensitivity and specificity for RA.

Studies in an experimental mouse model showed that tenosynovitis was the first sign of inflammation. ${ }^{15}$ Infiltration of the tendon sheaths by granulocytes and macrophages was the first pathological event in the preclinical phase; only few T cells were present and B cells were initially absent (figure 1D). Hyperplasia of the joint synovial lining was observed at the onset of clinical arthritis but not in the preclinical disease. ${ }^{15}$ The question if tenosynovitis is also the initiating feature of arthritis in humans with RA is still unsolved. However, a serial MRI study in pre-RA revealed that tenosynovitis and synovitis occurred very early, before the development of clinical arthritis and erosions. ${ }^{16}$ The notion that tenosynovitis is a very early feature of RA is further supported by the consistent finding that tenosynovitis is an independent predictor for developing RA in patients with clinically suspect arthralgia and undifferentiated arthritis, whereas synovitis is not constantly predictive in multivariate analysis (online supplementary table).

Finally we explored whether tenosynovitis contributes to symptoms and signs that are characteristic of RA. A summary of currently available data reveals that tenosynovitis is related to
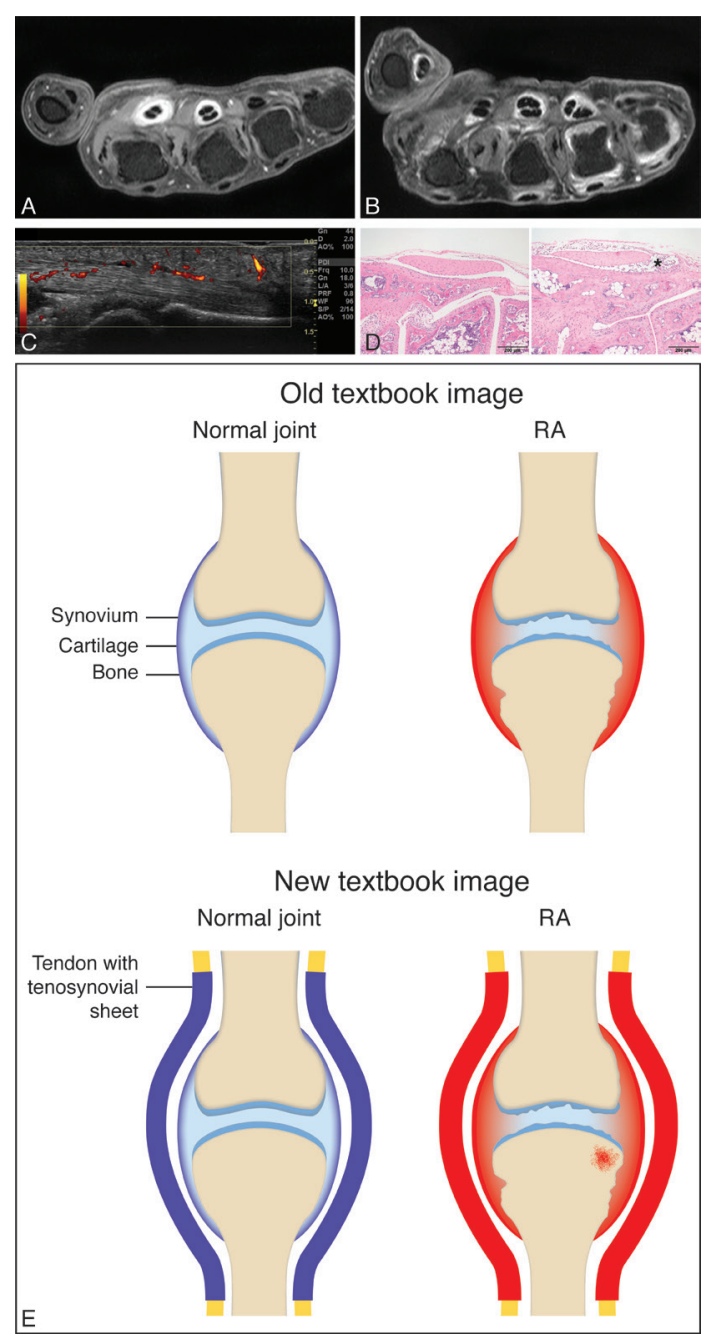

Figure 1 Tenosynovitis as an early trait in RA $(A-C)$ and experimental arthritis (D), and the proposed new textbook image of RA including tenosynovitis (E). (A-B) MRI (axial plane after contrast enhancement, 1.5T MRI) of two patients with early RA with flexor tenosynovitis at MCP 2 and $3(A)$ and flexor tenosynovitis at MCP 1, 3 and 4, and synovitis at MCP 4 and 5 (B). (C) Ultrasound (longitudinal plane) in a patient with early RA showing flexor tenosynovitis at MCP 2. (D) $\mathrm{H} \& \mathrm{E}-$ stained transverse section planes of the hind paw of 4-week-old wild-type (left) and hTNFtg (right) arthritis mice with tenosynovitis (*infiltration of lymphocytes and inflammation of the tendon sheath) in the preclinical phase of arthritis (magnification 100x). (E) Proposed new textbook image with tenosynovitis and osteitis. MCP, metacarpophalangeal; RA, rheumatoid arthritis.

the presence of joint swelling, joint tenderness, morning stiffness and functional impairments in RA and in earlier disease phases (online supplementary table). Associations were independent of possible concomitant imaging-detected synovitis.

To summarise, tenosynovitis at the level of small joints has high sensitivity and specificity for early RA. Tenosynovitis occurs early during RA development. It underlies symptoms and signs that are characteristic of RA, both in preclinical stages and in clinical RA. Based on this we propose that, in addition to synovitis and structural damage, future textbook images from now on also depict tenosynovitis as a classic trait of RA, as portrayed in figure 1E. In addition, if classification criteria for the earliest phases of RA were to be derived or modified, tenosynovitis could be included. 
Cleo Rogier, ${ }^{1}$ Silvia Hayer, ${ }^{2}$ Annette van der Helm-van Mil $\odot{ }^{1,3}$

${ }^{1}$ Rheumatology, Erasmus Medical Center, Rotterdam, Zuid-Holland, The Netherlands ${ }^{2}$ Division of Rheumatology, Medical University of Vienna, Vienna, Austria

${ }^{3}$ Rheumatology, Leiden University Medical Center, Leiden, The Netherlands

Correspondence to Professor Annette van der Helm-van Mil, Rheumatology, Leiden University Medical Center, Leiden 2300 RC, The Netherlands; A.H.M.van_der_Helm@lumc.nl

\section{Handling editor Gerd R Burmester}

Acknowledgements We acknowledge $G$ Kracht from the Department of Radiology at LUMC for his help in preparing the figure.

Contributors All authors wrote the manuscript. AvdH-vM supervised the process. Competing interests None declared.

Patient consent for publication Not required.

Provenance and peer review Not commissioned; externally peer reviewed.

\section{(2) OPEN ACCESS}

Open access This is an open access article distributed in accordance with the Creative Commons Attribution 4.0 Unported (CC BY 4.0) license, which permits others to copy, redistribute, remix, transform and build upon this work for any purpose, provided the original work is properly cited, a link to the licence is given, and indication of whether changes were made. See: https://creativecommons.org/ licenses/by/4.0/.

(c) Author(s) (or their employer(s)) 2020. Re-use permitted under CC BY. Published by BMJ.

- Additional material is published online only. To view please visit the journal online (http://dx.doi.org/10.1136/annrheumdis-2019-216350).

\section{Check for updates}

To cite Rogier C, Hayer S, van der Helm-van Mil A. Ann Rheum Dis 2020;79:546-547.

Received 20 September 2019

Revised 29 November 2019

Accepted 12 December 2019

Published Online First 19 December 2019

Ann Rheum Dis 2020;79:546-547. doi:10.1136/annrheumdis-2019-216350

ORCID ID

Annette van der Helm-van Mil http://orcid.org/0000-0001-8572-1437

\section{REFERENCES}

1 Dakkak Y, Jansen F, DeRuiter M, et al. Tenosynovitis at the metatarsophalangeal joints, a novel feature of ra: Results from an anatomical and large magnetic resonance imaging study of tendon sheaths of the forefoot [abstract]. Arthritis Rheumato/2019;71.

2 Niemantsverdriet E, van der Helm-van Mil AHM. Imaging detected tenosynovitis of metacarpophalangeal and wrist joints: an increasingly recognised characteristic of rheumatoid arthritis. Clin Exp Rheumatol 2018:36:131-8.

3 Kaibara N, Yamada H, Shuto T, et al. Comparative histopathological analysis between Tenosynovitis and joint synovitis in rheumatoid arthritis. Histopathology 2008;52:856-64.

4 Stewart NR, McQueen FM, Crabbe JP. Magnetic resonance imaging of the wrist in early rheumatoid arthritis: a pictorial essay. Australas Radiol 2001;45:268-73.

5 Eshed I, Feist E, Althoff CE, et al. Early rheumatoid arthritis-do we really know what it means? consistency and distribution of MRI findings according to different definitions for early rheumatoid arthritis. Clin Rheumatol 2011;30:551-5.

6 Filippucci E, Gabba A, Di Geso L, et al. Hand tendon involvement in rheumatoid arthritis: an ultrasound study. Semin Arthritis Rheum 2012;41:752-60.

7 Navalho M, Resende C, Rodrigues AM, et al. Bilateral evaluation of the hand and wrist in untreated early inflammatory arthritis: a comparative study of ultrasonography and magnetic resonance imaging. J Rheumatol 2013:40:1282-92.

8 Nieuwenhuis WP, Krabben A, Stomp W, et al. Evaluation of magnetic resonance imaging-detected tenosynovitis in the hand and wrist in early arthritis. Arthritis Rheumatol 2015;67:869-76.
9 Wakefield RJ, O'Connor PJ, Conaghan PG, et al. Finger tendon disease in untreated early rheumatoid arthritis: a comparison of ultrasound and magnetic resonance imaging. Arthritis Rheum 2007;57:1158-64.

10 Mo Y, Yang Z-H, Wang J-W, et al. FRI0623 MRI-detected digit flexor tenosynovitis in bilateral proximal interphalangeal joints contribute to joint tenderness in patients with early rheumatoid arthritis. Ann Rheum Dis 2019;78:1008-9.

11 Kleyer A, Krieter M, Oliveira I, et al. High prevalence of tenosynovial inflammation before onset of rheumatoid arthritis and its link to progression to RA-A combined MRI/CT study. Semin Arthritis Rheum 2016;46:143-50.

12 Trickey J, Sahbudin I, Bortoluzzi A, et al. THU0621 very low prevalence of ultrasound determined tendon abnormalities in healthy subjects throughout the age range: OMERACT ultrasound minimal disease study. Ann Rheum Dis 2019;78.

13 Mangnus L, van Steenbergen HW, Reijnierse M, et al. Magnetic resonance imagingdetected features of inflammation and erosions in symptom-free persons from the general population. Arthritis Rheumatol 2016;68:2593-602.

14 Mangnus L, Schoones JW, van der Helm-van Mil AHM. What is the prevalence of MRI-detected inflammation and erosions in small joints in the general population? A collation and analysis of published data. RMD Open 2015;1:e000005.

15 Hayer S, Redlich K, Korb A, et al. Tenosynovitis and osteoclast formation as the initial preclinical changes in a murine model of inflammatory arthritis. Arthritis Rheum 2007:56:79-88.

16 Ten Brinck RM, van Steenbergen HW, van der Helm-van Mil AHM. Sequence of joint tissue inflammation during rheumatoid arthritis development. Arthritis Res Ther $2018 ; 20$.

\section{Retinal vasculometric characteristics and their associations with polymyalgia rheumatica and giant cell arteritis in a prospective cohort: EPIC- Norfolk Eye Study}

Both polymyalgia rheumatica (PMR) and giant cell arteritis (GCA) have been associated with an increased future risk of cardiovascular disease (CVD). ${ }^{1}$ However, it remains uncertain whether this is a consequence of inflammatory disease or relates to a common underlying mechanism. Retinal vascular images are a sensitive measures of vascular health, which are emerging as important biomarkers of future cardiovascular risk with changes affecting arterioles and venules. ${ }^{2}$ In this study, we assess whether vasculometric features associated with CVD are detectable prior to the onset of PMR and GCA.

We analysed data from initially healthy subjects enrolled in the EPIC-Norfolk Study, a prospective population-based cohort which enrolled participants between the years 1993 and $1997 .{ }^{3}{ }^{4}$ Digital photographs of the retinal fundus were taken of 8112 participants between 2004 and 2011 using a TRC-NW6S non-mydriatic retinal camera and IMAGEnet Telemedicine System (Topcon Corporation, Tokyo, Japan) with a 10 MP Nikon D80 camera (Nikon Corporation, Tokyo, Japan). Retinal vessel widths were measured using the QUARTZ (QUantitative Analysis of Retinal vessel Topology and siZe) programme. ${ }^{5}$ The fully automated algorithm uses an ensemble classifier of bagged decision trees to allocate vessels into arterioles and venules at $80 \%$ probability and calculates summary measures for each participant with an averaged measure between right and left eyes.

Cases of PMR and GCA were identified by three methods: (1) free text questionnaire responses at enrolment, and thereafter, 18 months, 3, 10 and 13 years; (2) linkage to hospital electronic discharge summaries containing International Classification of Diseases (ICD) codes (3) linkage to keyword searches (polymyalgia or rheumatica or giant or arteritis) of out-patient clinic letters. To be identified as PMR or GCA, participants were required to have received at least two prescriptions for oral glucocorticoids within 6 months following their diagnosis. 
Table 1 Retinal vasculometric characteristics and their association to diagnoses of PMR and GCA

\begin{tabular}{|c|c|c|c|}
\hline & Incident cases* & $\begin{array}{l}\text { Incident cases meeting } \\
\text { classification sets }\end{array}$ & Control $n=5477$ \\
\hline PMR (n) & 30 & 24 & \\
\hline Venular width $(\mu \mathrm{m})$ and SD & 96.6 SD 12.5 & 100.0 SD 11.3 & 91.1 SD 10.6 from 5036 controls \\
\hline Difference in venular width $(\mu \mathrm{m})(95 \% \mathrm{Cl}) 80 \%$ probability $\dagger$ & $5.5(1.7$ to 9.3$) p=0.005$ & $8.9(4.7$ to 13.2$) p=<0.001$ & \\
\hline $\begin{array}{l}\text { Adjusted for age at time of retinal photograph capture } \\
\text { and sex }\end{array}$ & $4.4(0.7$ to 8.2$) p=0.021$ & $7.8(3.6$ to 12.0$) p=<0.001$ & \\
\hline Arteriolar width $(\mu \mathrm{m})$ and SD & 75.6 SD 7.6 & 76.9 SD 7.8 & 75.0 SD 6.3 from 5037 controls \\
\hline Difference in arteriolar width $(\mu \mathrm{m})(95 \% \mathrm{Cl}) 80 \%$ probability $\dagger$ & $0.7(-1.6$ to 2.9$) p=0.575$ & $0.6(-1.6$ to 2.9$) p=0.57$ & \\
\hline $\begin{array}{l}\text { Adjusted for age at time of retinal photograph capture } \\
\text { and sex }\end{array}$ & $1.0(-1.2$ to 3.3$) p=0.366$ & $1.1(-1.1$ to 3.4$) p=0.32$ & \\
\hline GCA (n) & 16 & 13 & \\
\hline Venular width $(\mu \mathrm{m})$ and SD & 93.0 SD 9.4 & 93.7 SD 10.3 & 91.1 SD 10.6 from 5036 controls \\
\hline Difference in venular width $(\mu \mathrm{m})(95 \% \mathrm{Cl}) 80 \%$ probability $\uparrow$ & $1.9(-3.3$ to 7.1$) p=0.47$ & $2.6(-3.2$ to 8.4$) p=0.38$ & \\
\hline $\begin{array}{l}\text { Adjusted for age at time of retinal photograph capture } \\
\text { and sex }\end{array}$ & $1.1(-4.1$ to 6.2$) p=0.68$ & $1.5(-4.2$ to 7.2$) p=0.60$ & \\
\hline Arteriolar width $(\mu \mathrm{m})$ and SD & 74.4 SD 5.9 & 73.8 SD 6.0 & 75.0 SD 6.3 from 5037 controls \\
\hline $\begin{array}{l}\text { Differences in arteriolar width }(\mu \mathrm{m})(95 \% \mathrm{Cl}) 80 \% \\
\text { probability } \dagger\end{array}$ & $-0.6(-3.6$ to 2.5$) p=0.73$ & $-1.2(-4.7$ to 2.2$) p=0.48$ & \\
\hline $\begin{array}{l}\text { Adjusted for age at time of retinal photograph capture } \\
\text { and sex }\end{array}$ & $-0.03(-3.1$ to 3.0$) p=0.98$ & $-0.7(-4.1$ to 2.7$) p=0.70$ & \\
\hline
\end{tabular}

*Incident cases-median time period 2.9 years between retinal image capture and subsequent diagnosis with $>75 \%$ having an interval of $>1$ year. tProbability of vascular segment type (arteriole or venule) weighted by segment length, $95 \% \mathrm{Cl}$.

GCA, giant cell arteritis; PMR, polymyalgia rheumatica.

This approach follows classification methodology validated in the Clinical Practice Research Datalink. ${ }^{6}$ Cases were excluded from analysis if the diagnosis in the case record was refuted or changed within the first 6 months. Case assignment was carried out independently by two rheumatologists (MY, RW). Only incident cases with retinal images captured before their PMR or GCA diagnosis were included.

Among 5532 participants who had retinal images analysable by QUARTZ, we identified 30 cases of incident PMR (median age at diagnosis: 74.8 years, range $(60.5,87.0)$; mean erythrocyte sedimentation rate (ESR) at diagnosis: $48 \mathrm{~mm} /$ hour; $70.0 \%$ female) and an additional 16 cases of GCA (median age at diagnosis: 75.0 years, range $(62.1,84.0)$; mean ESR at diagnosis: $80 \mathrm{~mm} /$ hour; $81.3 \%$ female). Vasculometric measures of those subsequently developing PMR (table 1), showed wider venules compared with controls $(5.5 \mu \mathrm{m}$ increased width 95\% CI 1.7 to $9.3, \mathrm{p}=0.004)$, which remained significant after adjustment for age at time of retinal image capture, and sex $(4.4 \mu \mathrm{m}$ wider, $95 \%$ CI 0.7 to $8.2, p=0.021)$. Some who were diagnosed with disease did not meet the classification criteria. A stronger association was present when the analysis was limited to those cases which fulfilled current classification criteria sets. Although, on average those subsequently developing GCA had wider venules compared with controls (93 vs $91.1 \mu \mathrm{m})$ the difference failed to reach statistical difference. There was no association between arteriolar measures for either PMR or GCA.

Using a novel retinal marker in a longitudinal populationbased setting, this analysis shows that participants who developed PMR already had wider retinal venules prior to the onset of their inflammatory disease. The data are limited by the relatively small number of cases with incident disease and need to be replicated in other settings. They nevertheless lend weight to the hypothesis that vascular changes precede the onset of PMR.
Max Yates $\odot,{ }^{1,2}$ Roshan Welikala, ${ }^{3}$ Alicja Rudnicka, ${ }^{4}$ Tunde Peto, ${ }^{5}$ Alexander J MacGregor, ${ }^{1}$ Anthony Khawaja, ${ }^{6}$ Richard Watts, ${ }^{2}$ David Broadway, ${ }^{7}$ Shabina Hayat, ${ }^{8}$ Robert Luben, ${ }^{9}$ Sarah Barman, ${ }^{3}$ Christopher Owen, ${ }^{10}$ Kay-Tee Khaw, ${ }^{11}$ Paul Foster ${ }^{12}$

${ }^{1}$ Centre for Epidemiology Versus Arthritis, University of East Anglia Norwich Medical School Centre for Epidemiology Versus Arthritis, Norwich, UK

${ }^{2}$ Department of Rheumatology, Ipswich Hospital, Ipswich, UK

${ }^{3}$ School of Computing and Information Systems, Kingston University School of Computing and Information Systems, Kingston upon Thames, UK

${ }^{4}$ Population Health Research Institute, St. George's, University of London, London, UK ${ }^{5}$ School of Medicine, Dentistry and Biomedical Sciences, Queen's University Belfast, Belfast, UK

${ }^{6}$ Glaucoma Department, Moorfields Eye Hospital NHS Foundation Trust, London, UK ${ }^{7}$ Ophthalmology, Norfolk and Norwich University Hospital NHS Trust, Norwich, UK

${ }^{8}$ Department of Public Health and Primary Care, University of Cambridge, Cambridge, UK

${ }^{9}$ Department of Public Health and Primary Care, University of Cambridge Department of Public Health and Primary Care, Cambridge, UK

${ }^{10}$ Population Health Research Institute, Saint George's University of London Division of Population Health Sciences and Education, London, UK

${ }^{11}$ Department of Public Health and Primary Care, Institute of Public Health, University of Cambridge School of Clinical Medicine, Cambridge, UK

${ }^{12}$ Intergrative Epidemiology Research Group, Joint Library of Ophthalmology Moorfields Eye Hospital and UCL Institute of Ophthalmology, London, UK

Correspondence to Dr Max Yates, University of East Anglia Norwich Medical School, Norwich, Norfolk NR4 7TJ, UK; maxyates@doctors.org.uk

\section{Handling editor Josef S Smolen}

Acknowledgements We thank the EPIC-Norfolk participants, funders of the EPICNorfolk cohort, GPs of Norfolk and Clinicians at the Norfolk and Norwich University Hospital.

Contributors MY: study design, data curation, analysis, drafting the manuscript. RoW: computer programmer for the QUARTZ group. AR: data analyst for generating vasculometric measures from QUARTZ derived measures of pixel width. TP: data controller of retinal images. AJM: input to study design and supervision of MY during his doctoral thesis. AK: ophthalomologist with input in to the design and execution of the third health check during which retinal images were taken. RAW: input to study design and secondary supervision of MY during his doctoral thesis. DB: ophthalomologist with input in to the design and execution of the third health check during which retinal images were taken. SH: research associate for EPIC with responsibility for the runing of the third health check. RL: research data manager 
responsibile for EPIC-Norfolk. SB: PI and lead of QUARTZ group. CO: data analyst for generating vasculometric measures from QUARTZ derived measures of pixel width. K-TK: PI of EPIC-Norfolk and custodian of the data. PF: PI of the third health check for EPIC. All PIs had input into the conception, design and undertaking of the study. All authors commented and edited previous drafts of the manuscript.

Funding EPIC-Norfolk infrastructure and core functions are supported by grants from the Medical Research Council (G1000143) and Cancer Research UK (C864/ A14136). The clinic for the third health examination was funded by Research into Ageing (262). The retinal vessel morphometry work was supported by the Medical Research Council Population and Systems Medicine Board (MR/L02005X/1) and British Heart Foundation (PG/15/101/31889). MY was Clinical Research Fellow Versus Arthritis. AK is a Wellcome Trust Clinical Research Fellow. Prof Foster has received additional support from the Richard Desmond Charitable Trust (via Fight for Sight) and the Department for Health through the award made by the National Institute for Health Research to Moorfields Eye Hospital and the UCL Institute of Ophthalmology for a specialist Biomedical Research Centre for Ophthalmology. None of the funding organisations had a role in the design or conduct of the research.

Competing interests None declared.

Patient consent for publication Not required.

Ethics approval The study was approved by the Norfolk Local Research Ethics Committee. Participants consented to the study and access to their records was granted. The procedures followed were in accordance with the ethical standards of the responsible committee on human experimentation and with the Helsinki Declaration of 1975, as revised in 1983. The study complies with the Declaration of Helsinki. The Norwich District Health Authority Ethics Committee approved the study and all participants gave written informed consent.

Provenance and peer review Not commissioned; externally peer reviewed.

Data availability statement All data requests and collaborations are reviewed and assessed by the EPIC-Norfolk Management Committee.

(C) Author(s) (or their employer(s)) 2020. No commercial re-use. See rights and permissions. Published by BMJ.

\section{Check for updates}

To cite Yates M, Welikala R, Rudnicka A, et al. Ann Rheum Dis 2020;79:547-549.

Received 25 July 2019

Revised 15 November 2019

Accepted 21 November 2019

Published Online First 29 November 2019

Ann Rheum Dis 2020;79:547-549. doi:10.1136/annrheumdis-2019-216078

ORCID ID

Max Yates http://orcid.org/0000-0003-3977-8920

\section{REFERENCES}

1 Ungprasert P, Koster MJ, Warrington KJ, et al. Polymyalgia rheumatica and risk of coronary artery disease: a systematic review and meta-analysis of observational studies. Rheumatol Int 2017:37:143-9.

2 Owen CG, Rudnicka AR, Welikala RA, et al. Retinal Vasculometry associations with cardiometabolic risk factors in the European prospective investigation of CancerNorfolk study. Ophthalmology 2019;126:96-106.

3 Day N, Oakes S, Luben R, et al. Epic-Norfolk: study design and characteristics of the cohort. European prospective investigation of cancer. Br J Cancer 1999;80 Suppl 1:95-103.

4 Khawaja AP, Chan MPY, Hayat S, et al. The EPIC-Norfolk eye study: rationale, methods and a cross-sectional analysis of visual impairment in a population-based cohort. BMJ Open 2013;3:e002684.

5 Welikala RA, Fraz MM, Foster PJ, et al. Automated retinal image quality assessment on the UK Biobank dataset for epidemiological studies. Comput Biol Med 2016;71:67-76.

6 Smeeth L, Cook C, Hall AJ. Incidence of diagnosed polymyalgia rheumatica and temporal arteritis in the United Kingdom, 1990-2001. Ann Rheum Dis 2006;65:1093-8.

\section{Dupilumab as a novel steroid-sparing treatment for lgG4-related disease}

IgG4-related disease (IgG4-RD) is a rare fibroinflammatory, multisystemic condition with a relapsing-remitting progression.
The level of serum IgG4 correlates with inflammatory activity and organ involvement. ${ }^{1}$ Glucocorticoids are first line for IgG4$\mathrm{RD}$, but there are numerous adverse effects with chronic use. ${ }^{2}$ Dupilumab is a monoclonal antibody that acts on the interleukin 4 (IL-4) receptor alpha, shared by the IL-4 and IL-13 receptors. ${ }^{1}$ IL-4 causes isotype switching from IgM to IgG4 and IL-13 is implicated in fibrosis. ${ }^{3}$ Thus, it was postulated by the authors to investigate dupilumab as a novel steroid-sparing treatment for IgG4-RD.

A 67-year-old man with no known allergies and a history of sensory neural hearing loss, recurrent bronchitis, spinal stenosis, moderate positional obstructive sleep apnoea, asthma, atopic dermatitis (which caused swelling around his eyes) and allergic rhinoconjunctivitis underwent extensive investigations over the past 2 years due to suspected IgG4-RD.

The patient's initial complaint was pruritic erythematous lesions on the legs, arms, chest and palms. Further investigations revealed parotitis, sinusitis, normocytic anaemia and eosinophilia. An MRI showed retroperitoneal and genitourinary fibrosis (figure 1A). Total $\mathrm{IgG}$ and $\mathrm{IgG}_{4}$ levels were found to be $32.40 \mathrm{~g} / \mathrm{L}$ and $20.60 \mathrm{~g} / \mathrm{L}$, respectively. The patient had a prostate biopsy which revealed 50 IgG4 cells per high power field and an IgG4 $+/ \mathrm{IgG}+$ cell ratio of $40 \%$. This result is exactly borderline as per the IgG4-RD comprehensive diagnostic criteria, ${ }^{4}$ making the result of the biopsy probable for IgG4-RD. Interventional radiologists determined the retroperitoneal fibrosis to be inaccessible for biopsy and the patient declined a repeat prostate biopsy. Although the biopsy was borderline, given that the imaging, clinical features and laboratory investigations fulfilled the remainder of the comprehensive diagnostic criteria (1 to $3 \mathrm{a}$ ), IgG4-RD was the consensus diagnosis. ${ }^{4}$

A treatment plan of a $40 \mathrm{mg}$ daily dose of prednisone was suggested by rheumatology, with the option of adding the adjuvant immunosuppressant azathioprine. The patient was on $40 \mathrm{mg}$ prednisone daily but declined other agents due to the risk of adverse effects.

Laboratory investigations revealed haemoglobin counts of $131 \mathrm{~g} / \mathrm{L}$ (normal range 135-175 g/L), haematocrit levels of $0.391 \mathrm{~L} / \mathrm{L}$ (normal range $0.4-0.5 \mathrm{~L} / \mathrm{L}$ ), eosinophil levels of $1.4 \times 10^{9}$ cells $/ \mathrm{L}$ (normal range $0.0-0.5 \times 10^{9} / \mathrm{L}$ ) and alkaline phosphatase serum levels of $34 \mathrm{U} / \mathrm{L}$ (normal range 40-129 U/L). On examination, atopic dermatitis was present with $50 \%$ body surface area (BSA) involvement with an Investigator Global Assessment (IGA) score of 4, indicating severe disease. An initial $600 \mathrm{mg}$ subcutaneous injection of dupilumab, followed by a $300 \mathrm{mg}$ subcutaneous injection every other week for 12 months was given to treat atopic dermatitis, asthma and potentially IgG4-RD.

After 3 months on dupilumab, the patient's eye swelling resolved, and his skin and asthma noticeably improved to IGA1 and $<10 \%$ BSA. Both total IgG and IgG4 levels reduced substantially to $19.41 \mathrm{~g} / \mathrm{L}$ and $11.43 \mathrm{~g} / \mathrm{L}$, respectively. After 12 months on dupilumab, the patient's retroperitoneal fibrosis improved dramatically corresponding with the decreased IgG4 levels (figure 1B). It is noted that dupilumab is in itself an IgG4 monoclonal antibody.

Current treatments for IgG4-RD are associated with many long-term adverse effects. The first-line treatments are glucocorticoids, second-line treatments are chemotherapeutic immunosuppressants and the third-line treatment is B-cell depleting rituximab, an anti-CD20 monoclonal antibody. The adverse effects associated with these therapies include increased risks of infection and potentially lasting immune deficiency. ${ }^{5}$

Dupilumab has been observed to be safe with long-term use across multiple indications. ${ }^{6}$ In this patient, IgG4-RD was 

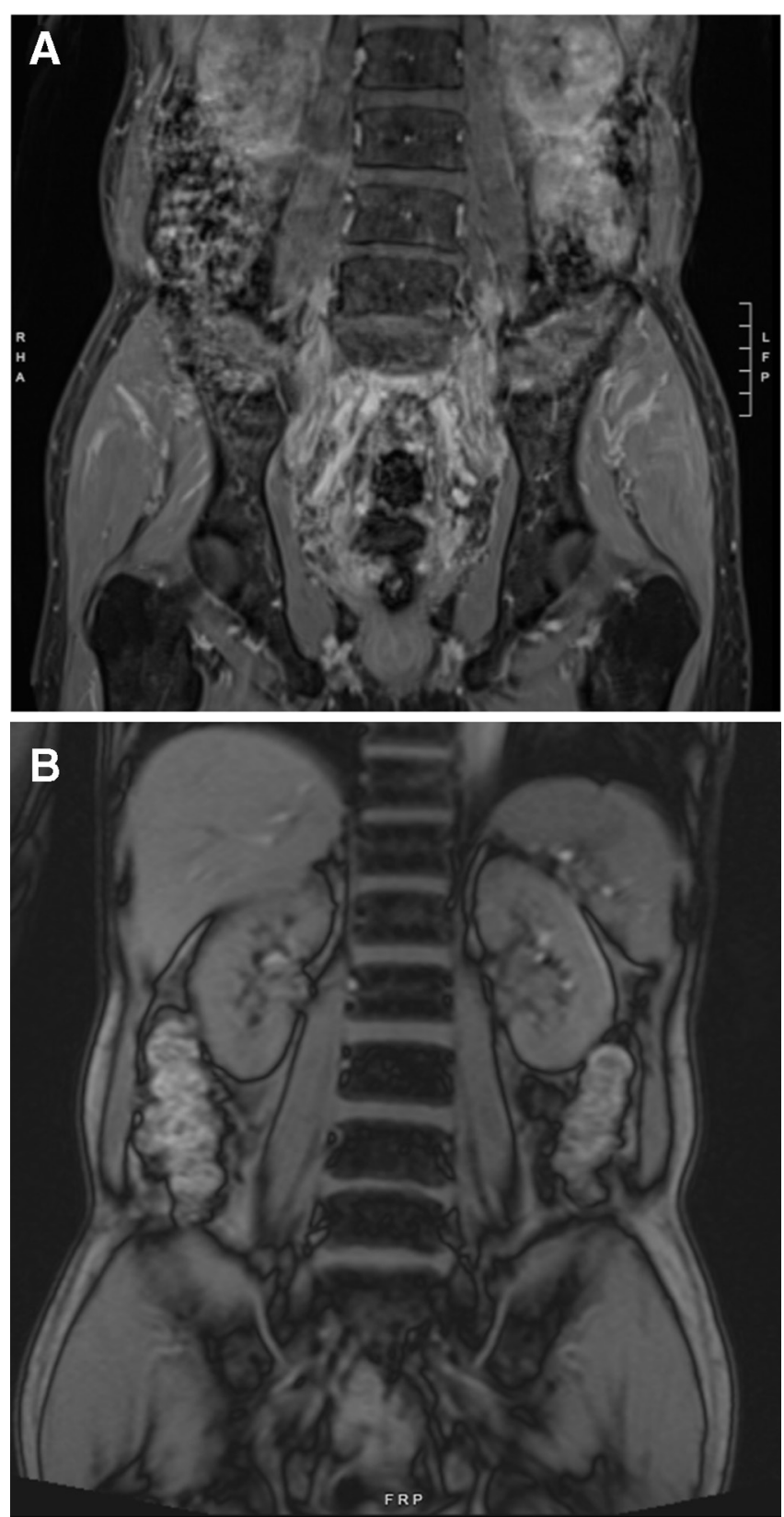

Figure 1 (A) Patient's initial MRI findings before dupilumab treatment showed extensive retroperitoneal and extraperitoneal fibrosis. (B) MRI taken approximately 1 year after dupilumab treatment showed dramatic resolution of fibrosis.

controlled with no further relapses across all affected organ systems with no significant long-term adverse events and prednisone withdrawal within 2 months. Dupilumab's efficacy in the treatment of IgG4-RD also highlights the importance of IL-4 and IL-13 in the pathological mechanisms of this condition.

\section{Rachel S Simpson ${ }^{1}{ }^{1}$ Stephanie Ka Ching Lau, ${ }^{1,2}$ Jason Kihyuk Lee ${ }^{1}$ \\ ${ }^{1}$ Toronto Allergists, Toronto, Ontario, Canada \\ ${ }^{2}$ Faculty of Medicine, University of Ottawa, Ottawa, Ontario, Canada}

Correspondence to Rachel S Simpson, Toronto Allergists, Toronto, ON M5G 1E2, Canada; rachel.simpson@queensu.ca

Correction notice This article has been corrected since it published Online First. Figure 1 has been updated.

\section{Handling editor Josef S Smolen}

Contributors RSS undertook the primary duties in writing the manuscript, including the case description and discussion as well as submission and editing of the manuscript. SL wrote the introduction of the manuscript and was involved in the editing process. JKL was the physician who identified and managed the case, oversaw the manuscript writing and edited the manuscript.

Funding The authors have not declared a specific grant for this research from any funding agency in the public, commercial or not-for-profit sectors.

Competing interests JKL reports receiving research grants, clinical research trial funding and speaker fees from Novartis, Sanofi, Regeneron, Sanofi Genzyme, Astrazeneca, Genentech, Roche and GlaxoSmithKline as well as personal fees from ALK, grants and personal fees from Aralez, and grants and personal fees from Pediapharm. RSS and SL report having nothing to disclose.

\section{Patient consent for publication Obtained.}

Provenance and peer review Not commissioned; externally peer reviewed. (C) Author(s) (or their employer(s)) 2020. No commercial re-use. See rights and permissions. Published by BMJ.

\section{(D) Check for updates}

To cite Simpson RS, Lau SKC, Lee JK. Ann Rheum Dis 2020;79:549-550.

Received 24 September 2019

Revised 10 December 2019

Accepted 11 December 2019

Published Online First 19 December 2019

Ann Rheum Dis 2020;79:549-550. doi:10.1136/annrheumdis-2019-216368

ORCID iD

Rachel S Simpson http://orcid.org/0000-0003-1779-4049

\section{REFERENCES}

1 Kamisawa T, Zen Y, Pillai S, et al. Igg4-Related disease. The Lancet 2015;385:1460-71.

2 Shirakashi M, Yoshifuji H, Kodama Y, et al. Factors in glucocorticoid regimens associated with treatment response and relapses of IgG4-related disease: a multicentre study. Sci Rep 2018:8:10262.

3 Gandhi NA, Pirozzi G, Graham NMH, et al. Commonality of the IL-4/IL-13 pathway in atopic diseases. Expert Rev Clin Immunol 2017;13:425-37.

4 Umehara H, Okazaki K, Masaki Y, et al. Comprehensive diagnostic criteria for lgG4related disease (IgG4-RD), 2011. Mod Rheumatol 2012;22:21-30.

5 Kaplan B, Kopyltsova Y, Khokhar A, et al. Rituximab and immune deficiency: case series and review of the literature. J Allergy Clin Immunol 2014;2:594-600.

6 Blauvelt A, de Bruin-Weller M, Gooderham M, et al. Long-Term management of moderate-to-severe atopic dermatitis with dupilumab and concomitant topical corticosteroids (liberty AD CHRONOS): a 1-year, randomised, double-blinded, placebocontrolled, phase 3 trial. The Lancet 2017;389:2287-303. 